\title{
Capture Reagent and Strategy for Retrieving Albumin-Bound Ligands from Plasma
}

\author{
Megan M. Koslen', Matthew W. Eskew ${ }^{1}$, Vincent Pinkert'1, Huyen Hoang1, Fidelis Manyanga', \\ William L. Dean², Jonathan B. Chaires², Albert S. Benight ${ }^{1,3}$
}

${ }^{1}$ Department of Chemistry, Portland State University, Portland, Oregon, USA

${ }_{2}^{2}$ James Graham Brown Cancer Center, University of Louisville, Louisville, Kentucky, USA

${ }^{3}$ Department of Physics, Portland State University, Portland, Oregon, USA

Email: abenight@pdx.edu

How to cite this paper: Koslen, M.M., Eskew, M.W., Pinkert, V., Hoang, H., Manyanga, F., Dean, W.L., Chaires, J.B. and Benight, A.S. (2019) Capture Reagent and Strategy for Retrieving Albumin-Bound Ligands from Plasma. Advances in Biological Chemistry, 9, 110-134.

https://doi.org/10.4236/abc.2019.93009

Received: April 12, 2019

Accepted: June 25, 2019

Published: June 28, 2019

Copyright $\odot 2019$ by author(s) and Scientific Research Publishing Inc. This work is licensed under the Creative Commons Attribution International License (CC BY 4.0).

http://creativecommons.org/licenses/by/4.0/

\begin{abstract}
A capture strategy is described and demonstrated for retrieving ligand entities in plasma that bind Human Serum Albumin. The method has applications for both exogenous and endogenous ligands. Exogenous ligands include drug candidates, performance enhancing drugs and toxic nerve agents that also interact quite strongly with HSA. Endogenous ligands are natural circulating compounds whose abundance corresponds to normal hemostasis or elevated levels that could be disease-specific molecular biomarkers. Melting curves of plasma solutions measured by differential scanning calorimetry produce "so-called" plasma thermograms that are physical signatures of the plasma solution. Patterns displayed by thermograms can be sensitive indicators of the presence of abnormal levels of exogenous and endogenous ligand components. Effects of ligand interactions on thermodynamic stability of proteins in plasma that they bind, primarily HSA, manifest on the plasma thermogram. The capture strategy is demonstrated for HSA binding in plasma of four "ideal" ligands of different types. The particular ligands were naproxen, bromocresol green, short double stranded and single strand DNA. Thermogram shapes and features were sensitive to the presence of ligands as thermograms of mixtures of plasma and HSA with these ligands were significantly different than thermograms of plasma or HSA alone. These results demonstrated directly that significant perturbations of plasma thermograms corresponded to ligand interactions with HSA in plasma.
\end{abstract}

\section{Keywords}

Human Serum Albumin (HSA), Differential Scanning Calorimetry (DSC), Protein Thermodynamic Stability, Analyte Capture 


\section{Introduction}

Human plasma is a complex fluid comprised of a variety of molecular cellular components constantly perfusing tissues throughout the entire body. [1] included in this process is distribution of exogenous therapeutic compounds and endogenous circulating components released in the interstitial fluid. Endogenous compounds might include metabolic and cellular degradation products that can be associated with health status. For example in cancer, tumors constantly shed cell remnants releasing disease-specific proteins and protein fragments into plasma. Endogenous circulating components might interact with HSA and alter thermograms. In addition to being a transport medium for exogenous compounds, plasma contains an enormous repository of endogenous cellular components that can bind HSA and also can be directly reflective of collective physiological status and indicative of normal health.

The process of pre-clinical drug development efforts requires that new chemical entities (NCE) identified as potential drug candidates be both potent and bioavailable. To be potent an NCE must have specific and sufficient binding strength to its desired target. Bioavailability of the NCE requires the compound be properly absorbed, distributed, metabolized, excreted and not toxic or that it, must possess favorable ADME/Tox characteristics. An essential part of meeting these requirements is how the NCE interacts with Human Serum Albumin, HSA.

A key facet in bioavailability of an NCE is the ability to delay metabolism by the liver or clearance from the body by the kidneys. Both pharmaceuticals and biomolecules utilize protein binding to protect them from clearance [2]. Specifically, plasma proteins are primarily responsible for binding these entities to protect them from clearance and to distribute them throughout the body. One of the challenges is finding ways of manipulating the ability of an NCE to bind plasma proteins and this has become a key aim in improving pharmacokinetics of short lived biomolecules [3]. In this regard, any attempt to manipulate the ability of an NCE to bind plasma proteins must first begin by gaining a firm understanding of the strength and specificity of interactions between the compound and components of the plasma proteome.

At the center of any approach to plasma protein analysis is HSA since it is the primary component of plasma by mass and comprises $60 \%$ of the total protein in plasma [4]. HSA is a circulating sponge and transporter of many components in the blood [5]. Central to its function, HSA binds a variety of ligands (peptides, proteins, lipids, etc.) and serves to circulate entities that bind it (cargo) in the blood to various locations, organelles and organs throughout the body. Associated with these functions there are a multiplicity of reactive sites on HSA with a known binding affinity for a large variety of different ligands [4] [6] [7].

The secondary structure of HSA contains multiple helical subdomains suitable for binding a variety of ligands. Sudlow designated and characterized the primary drug binding sites on the HSA structure as sites I and II [8]. Binding capacity 
of HSA allows it to accommodate quantities of ligands exceeding their solubility limit in plasma [9]. A variety of analytical methods have been employed to study the binding sites on HSA and their interactions with ligands. Methods that have been employed include but are not limited to; affinity chromatography [10], capillary electrophoresis [5] [11] fluorescence and UV/vis spectroscopy [6] [12], nuclear magnetic resonance (NMR) [13], and mass spectrometry [14] [15]. Most of these methods have been hindered by their limited ability to only analyze simple solutions of individual proteins or protein fragments; providing little insight into interactions of these molecules within the wider network of the plasma proteome.

Over the past decade, a number of groups have pursued a unique approach to plasma analysis based on differential scanning calorimetry (DSC) [16] [17] [18] [19] [20]. This novel approach provides an extremely attractive means of plasma analysis. Plasma thermograms measured by DSC are sensitive to mass, abundance, and effects of ligand (exogenous and endogenous) binding. In essence, plasma thermograms provide a system-wide snapshot of the status of the plasma proteome (and ligands therein) in terms of thermodynamic stability of the major plasma proteins and circulating ligands that bind them. Classification of plasma using DSC contrasts with more standard methods based on charge, molecular weight (MW), or antigenic activity and provides a new perspective from which to analyze plasma. The readout of a DSC experiment is a plot of the heat capacity, $\Delta \mathrm{Cp}$ versus temperature, or thermogram. As the most abundant plasma protein $(60 \%)$ the fractional contribution of HSA comprises a significant portion of the overall signal making up the plasma thermogram.

The present study was undertaken as part of an effort to investigate and perhaps more clearly define, from a physical perspective, the underlying mechanism responsible for specific perturbations of plasma thermograms brought about by ligand interactions. The current hypothesis is that ligand interactions with HSA in plasma and their associated effects on HSA thermostability have a major impact on perturbations of the plasma thermogram. Both exogenous ligand binding and binding of endogenous ligands associated with various disease states can bind to HSA inducing perturbations of the plasma thermogram [21] [22] [23] [24]. Verifying this supposition requires a means to isolate ligands that bind HSA in plasma as supplied by the capture strategy. Results presented here clearly show for four different types of ligands that bind HSA in plasma, that these ligands can be captured and retrieved. In addition, that thermograms of mixtures of plasma or HSA with the same HSA-binding ligands are significantly different than thermograms of plasma or HSA alone.

The aim of the capture strategy is to isolate retrieved material (from interesting plasma samples) in sufficient quantities for extensive follow-on analysis, in particular DSC measurements. Effects of the retrieved, isolated material on just the HSA thermogram would directly demonstrate contributions of HSA/ligand interactions on the measured perturbed plasma thermogram. The degree to which the HSA thermogram is affected defines the extent of the plasma thermo- 
gram perturbation attributable to binding of HSA.

\section{Materials and Methods}

Protein samples: Human Plasma and Serum Albumin were purchased from Sigma Aldrich (St. Louis, MO) and received as lyophilized powder. Plasma was product number: P9523, lot number: SLBT0202. Human serum albumin (HSA) advertised as fatty acid and globulin free, $\geq 99 \%$ pure was lot number: SLBD7204V. Plasma and HSA stock solutions were prepared by re-suspending the appropriate amount of powder in buffer. Samples were prepared by diluting stock solutions to a final concentration of $1.5-2.0 \mathrm{mg} / \mathrm{mL}$.

Determination of Protein Concentrations: Protein concentrations were determined as previously described using the BCA method and the Protein Assay Kit (product \#23225, Thermal Fisher Scientific) [25].

Ligand Samples: Three different types of ligands were used in this study. They were: 1) naproxen (NAP); 2) bromocresol green (BCG) and 3) short single strand (ssDNA) and double stranded DNAs (dsDNA). BCG product number: 114359, lot number: $07896 \mathrm{HJ}$; and NAP product number: N8280, lot number: 040M1400V were purchased from Sigma Aldrich (St. Louis, MO).

The 25 base pair double stranded (25-mer) and the individual strands (25 R and $25 \mathrm{~L}$ ) that comprise it were purchased from IDT and received after having been subjected to their standard desalting routine. The 25R DNA sequence is 5'-CGA CAT GAC CTT GTC GCT AAC ATC C-3' (Ref. No. 165820905) DNA $25 \mathrm{~L}$ is the perfect complement of DNA $25 \mathrm{R}$; and DNA 25-MER, the 25 base pair duplex made from $25 \mathrm{R}+25 \mathrm{~L}$. $25 \mathrm{R}$ with a 5 ' cy-5 fluorescent label was also purchased from IDT and received as HPLC purified and desalted. Labeled 25-MER was prepared by incubating 5' cy-5 labeled $25 \mathrm{R}$ with its complement, $25 \mathrm{~L}$. To ensure all duplex molecules were labeled, the two strands were mixed with a slight excess of unlabeled strand in a 1:1.01 molar ratio. For mixtures of DNA single strands of $25 \mathrm{R}$ and $25 \mathrm{~L}$ solutions were heated to $90^{\circ}$ in a heat block, the heater was turned off and the sample was allowed to slowly cool and anneal back to room temperature.

Solvents and Reagents: Standard PBS buffer solutions contained $10 \mathrm{mM}$ potassium phosphate and $150 \mathrm{mM} \mathrm{NaCl}, \mathrm{pH}=7.4$. Total ionic concentrations of buffers were verified by electrical conductivity measurements. After preparation and prior to use buffer solutions were stored at $4^{\circ} \mathrm{C}$. TBST magnetic bead wash buffer was $20 \mathrm{mM}$ Tris- $\mathrm{HCl}, 150 \mathrm{mM} \mathrm{NaCl}$ and $0.1 \%$ Tween $20, \mathrm{pH}=7.5$. Retrieval high-salt wash buffer was $20 \mathrm{mM}$ Tris- $\mathrm{HCl}$ and $500 \mathrm{mM} \mathrm{NaCl}, \mathrm{pH}=7.5$. Isolation low-salt wash buffer was $20 \mathrm{mM}$ Tris- $\mathrm{HCl}, \mathrm{pH}=7.5$. SDS: $5 \%$ Sodium Dodecyl Sulphate, $50 \%$ glycerol and $12.5 \mathrm{mM}$ Tris- $\mathrm{HCl}, \mathrm{pH}=8.0$. Retrieval wash solution, 50:0.1:49.9 (v/v\%) Acetonitrile:Acetic Acid: $\mathrm{H}_{2} \mathrm{O}$. All solutions and buffers were prepared with nanopure deionized water. Chemicals and reagents were molecular biology grade or higher.

Gel Electrophoresis Staining: Stains-All was purchased from Sigma Aldrich 
(St. Louis, MO) (product number: E9379, lot number: BCBS0570V). Staining solution was $60 \% 20 \mathrm{mM}$ Tris- $\mathrm{HCl} \mathrm{pH}=8,20 \%$ isopropanol, $20 \% 0.1 \%$ Stains-All in formamide.

Preparation of the Capture Moiety: Biotin was attached to fatty acid free HSA using the EZ-Link Sulfo-NHS-Biotin kit (product number 21217 from Thermo Fisher Scientific) according to the supplier's instructions. For attachment reactions, a $10 \mathrm{mM}$ stock solution of Biotin was prepared by dissolving Biotin in water. A solution containing a 1:5 molar ratio of HSA:Biotin was prepared by adding appropriate amounts of the Biotin stock solution to an HSA solution at 2 $\mathrm{mg} / \mathrm{mL}$, and was stored at $4^{\circ} \mathrm{C}$ for at least 24 hours. When attachment reactions were complete, free (unattached) Biotin was removed using a Zeba ${ }^{\mathrm{TM}}$ spin desalting column (product number: 89892, lot number: RH236113A, Thermo Scientific). In this procedure, the column was equilibrated three times with $2 \mathrm{~mL}$ standard PBS buffer. An aliquot of $1.5 \mathrm{~mL}$ of the attachment reaction solution was then added directly to a spin column and retrieved. Sample volumes were such that several columns were required. Retrieved products from these runs were pooled. From the streptavidin coverage density of the magnetic beads, supplied by the manufacturer, binding capacity of the beads was estimated to be approximately $55 \mu \mathrm{g}$ of biotinylated protein per $\mathrm{mg}$ of beads.

Preparation of the Capture Reagent: Pierce ${ }^{\mathrm{TM}}$ streptavidin magnetic beads were purchased from Thermo Scientific (product number: 88816, lot number: SG249234). Magnetic beads were prepared according to the supplier's instructions, by rinsing $50 \mathrm{uL}(0.5 \mathrm{mg})$ of beads with $1 \mathrm{~mL}$ TBST wash buffer. After removal of the wash buffer, $300 \mathrm{uL}$ of the capture moiety was added to the beads and the mixture was incubated at $4^{\circ} \mathrm{C}$ for at least 24 hours. After incubation, the sample was placed under a magnetic field and excess capture moiety in the supernatant was removed. Remaining capture reagent was never allowed to completely dry and was stored in buffer for future use.

Gel Electrophoresis: DNA samples collected at different steps of the capture procedure were analyzed by electrophoresis on polyacrylamide gels. All electrophoresis experiments were performed using Lonza PAGEr ${ }^{\mathrm{TM}}$ Gold Precast Gels: Gradient, $10 \times 10 \mathrm{~cm}, 8 \%-16 \%$, purchased from Thermo-Fisher (BMA59519). Each supernatant fraction collected at different steps of the capture procedure were suspended in TAE running buffer and analyzed. In a typical experiment, 25 $\mu \mathrm{L}$ total volume of solution was loaded per lane (well capacity). Gels were run in TAE buffer ( $40 \mathrm{mM}$ Tris, $20 \mathrm{mM}$ Acetic Acid, $0.4 \mathrm{mM}$ EDTA) at a constant current of $20 \mathrm{~mA}$ for approximately three hours. Gels for analysis of DNA were stained with Stains-all solution, destained in water, removed, visualized and imaged on a flat-bed scanner. Gels for analysis of hot labeled cy5'-25MER DNA were visualized using a Typhoon ${ }^{\mathrm{TM}}$ Trio + phosphorimager (GE Healthcare).

High-Pressure LC and MS: Samples were analyzed for the presence of analyte (ligand) using HPLC-MS instrumentation consisting of an Accela HPLC system (Thermo Fisher Scientific) coupled to an electrospray ionization source 
and LTQ-Orbitrap Discovery high resolution mass spectrometer (Thermo Electron). Retrieved analyte samples were separated using a $50 \mathrm{~mm}$ Beta Basic 18 HPLC column (internal diameter $1 \mathrm{~mm}$; C18 $3 \mu \mathrm{m}$; Thermo Fisher Scientific). Each LC-MS analysis used $10 \mu \mathrm{L}$ of sample with a run time of 10 minutes.

Ligand samples were kept in the retrieval wash solution and loaded in buffer A $(0.1 \%(\mathrm{v} / \mathrm{v} \%)$ formic acid) and eluted using a linear 5 minute gradient (5\% $95 \%$ buffer B comprised of $0.1 \%(\mathrm{v} / \mathrm{v} \%)$ acetic acid, $99.9 \%$ (v/v\%) acetonitrile) held for 2 minutes at $95 \%(\mathrm{v} / \mathrm{v} \%)$ buffer B, followed by a 3 minute wash of $95 \%$ $(\mathrm{v} / \mathrm{v} \%)$ buffer A, $5 \%(\mathrm{v} / \mathrm{v} \%)$ buffer B. All flow rates were held constant at 500 $\mu \mathrm{L} / \mathrm{min}$ and the column temperature was maintained at $35^{\circ} \mathrm{C}$.

MS data was acquired using the combination of a low resolution ion trap and high resolution FTMS. Targeted values for detection of the ligands was set for a scan range of $100.00-750.00 \mathrm{~m} / \mathrm{z}$ and a resolution of 30,000 at $\mathrm{m} / \mathrm{z}=400$. Samples were ionized in negative mode with a spray voltage of $2.50 \mathrm{kV}$ and normalized collision energy of $35.0 \mathrm{eV}$.

MS Data Analysis: MS raw data files were analyzed using Xcalibur software version 4.1 (Thermo Scientific). MS data are displayed in standard form as plots of relative abundance versus the $\mathrm{m} / \mathrm{z}$ ratio. Isotope simulation of mass spectra identified target ligands with an allowed mass deviation of less than $20 \mathrm{ppm}$.

Differential scanning calorimetry: All DSC melting experiments were performed using a CSC Model 6100 Nano II-Differential Scanning Calorimeter (formerly Calorimetry Sciences Corporation, Provo UT, now TA Instruments). The average of three to five buffer scans collected over the temperature range from $0^{\circ} \mathrm{C}$ to $100^{\circ} \mathrm{C}$ served as the buffer baseline for analyzing scans of protein, ligand samples, and their mixtures. A temperature scan rate of $1^{\circ} \mathrm{C} / \mathrm{min}$ was employed. All DSC samples were prepared in standard PBS buffer with a protein concentration of approximately $2 \mathrm{mg} / \mathrm{ml}$ and incubated with ligand for 24 hours. The temperature range used for measuring DSC thermograms was typically from $25^{\circ} \mathrm{C}$ to $90^{\circ} \mathrm{C}$. For displayed thermograms, the range was $45^{\circ} \mathrm{C}$ to $90^{\circ} \mathrm{C}$ and all data was smoothed using a non-parametric local regression (LOESS) method.

In a DSC melting experiment, the supplemental power supplied to the sample cell (in $\mu \mathrm{W}$ ) necessary to keep the sample temperature equal to the reference temperature is continually monitored. Simultaneously, temperatures of the sample and reference cells are linearly increased at precisely the same rate. Supplemental power is directly related to the molar heat capacity at constant pressure, $\Delta \mathrm{Cp}$. Curves of $\Delta \mathrm{Cp}$ versus $\mathrm{T}$ provide an evaluation of the thermodynamic enthalpy. To enable direct comparisons in some cases, power $(\mu \mathrm{W})$ versus $\mathrm{T}$ plots (instead of $\Delta \mathrm{Cp}$ versus $\mathrm{T}$ curves) were used for the following reason.

In the standard analysis of solutions containing a single molecular species conversion of the raw signal in $\mu \mathrm{W}$ to $\Delta \mathrm{Cp}$ values requires precise knowledge and input of the sample mass $/ \mathrm{mL}$, cell volume, MW, and partial specific volume (PSV). For a mixture of molecules of different types, as is the case for HSA + DNA, where both components of the mixture have appreciable $\triangle \mathrm{Cp}$ values with some overlap over the same temperature range, application of the standard 
analysis, based on the presence of a single type of molecular species, precludes proper comparison. That is, composite melting curves of the mixtures can only be analyzed in the standard way assuming a single MW, i.e. either $66 \mathrm{kD}$ or $3-5$ $\mathrm{kD}$ for both HSA and DNA, and a single PSV for both, which is patently incorrect! To circumvent this limitation for comparison purposes, thermograms for

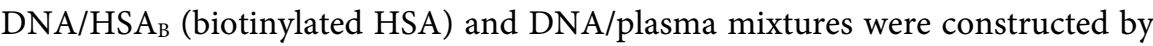
plotting total power in $\mu \mathrm{W}$ versus $\mathrm{T}$. These curves were normalized and compared to $\mu \mathrm{W}$ versus $\mathrm{T}$ to thermograms measured for $\mathrm{HSA}, \mathrm{HSA}_{\mathrm{B}}$, or plasma alone at precisely the same concentrations as in the mixtures. Using normalized curves constructed from $\mu \mathrm{W}$ (instead of $\Delta \mathrm{Cp}$ versus $\mathrm{T}$ ) provides a valid means for comparison, but also introduces a limitation on quantitative information obtained. That is, in order to establish an appropriate footing for comparison of composite melting curves of DNA/plasma and DNA/HSA $A_{B}$ mixtures, we lose the ability to quantitatively evaluate the molar thermodynamic enthalpies of the mixtures.

Analysis of DSC data was performed using the Nanoanalyze software package, version 3.7.5, provided by T.A. Instruments. Steps in the analysis procedure for analysis of $\mu \mathrm{W}$ versus $\mathrm{T}$ curves were precisely the same as reported for $\Delta \mathrm{Cp}$ versus $\mathrm{T}$ data. [25] For analysis of thermograms of the ligands (NAP, BCG, and DNA), HSA, biotinylated HSA ( $\mathrm{HSA}_{\mathrm{B}}$ ), and plasma alone, the standard analysis procedure was employed exactly as described previously [25]. Values of the calorimetric transition enthalpy, $\Delta \mathrm{H}_{\text {cal }}$, determined from the integrated area under the measured thermogram $\Delta \mathrm{Cp}(\mathrm{T})$ versus $\mathrm{T}$ curves were used to asses quality of HSA (and $\mathrm{HSA}_{\mathrm{B}}$ ) samples and characterize HSA/ligand complexes.

Analytical Ultracentrifugation: All sedimentation velocity experiments were performed in a Beckman Coulter Proteome Lab XL-A analytical ultracentrifuge (Beckman Coulter, Inc Brea, Ca) at $20^{\circ} \mathrm{C}, 50,000 \mathrm{rpm}$, and $260 \mathrm{~nm}$ in standard cells. A minimum of 100 scans were collected over 8 hours. Data was analyzed by SedFit using continuous $\mathrm{c}(\mathrm{s})$ distribution mode. Buffer density and viscosity were measured using a Paar DM55A density meter and Paar AMVn microviscometer.

Analytical ultracentrifugation (AUC) has been an established physical technique for over 50 years [26]. It provides high precision determinations of distributions of molecular populations and can detect significant binding events from measured S-values. Recent results from the AUC consortium demonstrated standardization and high precision of the technique using bovine serum albumin (BSA) which is very similar to HSA [27]. Our sample preparations of biotinylated $\mathrm{HSA}_{B}$ containing different levels of HSA:biotin attachment at ratios of 1:1, 1:5 and 1:10 were characterized by AUC. The procedure provides a highly accurate measurement of HSA dimer/monomer populations and MW of the different biotinylation levels and reveals significant changes in structure and conformation (if they exist) with increased biotinylation.

Capture Strategy: In this isolation scheme, biotinylated HSA acts as an affin- 
ity reagent for ligands in plasma that bind HSA. In the capture step, streptavidin coated magnetic beads are attached to biotinylated HSA then inserted into a plasma solution. With application of a magnetic field ligand-bound biotinylated HSA is retrieved. Captured HSA contains bound plasma components (ligands). Bound ligands are washed off the retrieved biotinylated HSA and subjected to further characterization and analysis by gel electrophoresis and MS.

Components: There are several components used in the capture strategy as depicted in Figure 1. The capture moiety (Figure 1(a)) is comprised of HSA with biotin attached to the surface. The capture moiety acts as an affinity reagent for capturing molecular components from plasma sample solutions. The retrieval moiety in Figure 1(b) is a magnetic bead, surface-coated with streptavidin. Coupling of the capture and retrieval moieties is achieved through the biotin-streptavidin linkage, resulting in the fully complete capture reagent shown in Figure 1(c). Coupled reagents are separated from uncoupled reactants using a magnet while pulling off the supernatant; the magnet is removed, and the retained coupled capture reagent is re-suspended in appropriate buffer.

1) The Capture Moiety. The capture moiety is biotinylated HSA ( $\left.\mathrm{HSA}_{B}\right)$ made using the N-Hydroxy Succinate Biotin (N-HS) reagent, which attaches biotin to primary amines of lysine resides [25]. Previous studies indicated that biotin attachment has a small but measureable effect on $\mathrm{HSA}_{\mathrm{B}}$ thermodynamic stability [25]. Relative levels of HSA biotinylation were evident on respective thermograms and produced small incremental changes with increased biotinylation. With increased biotinylation, thermodynamic stability incrementally increased up to a ratio of 10:1 biotin:HSA. These results verified sensitivity of DSC to detect the difference in relative amounts of biotinylation and indicated that

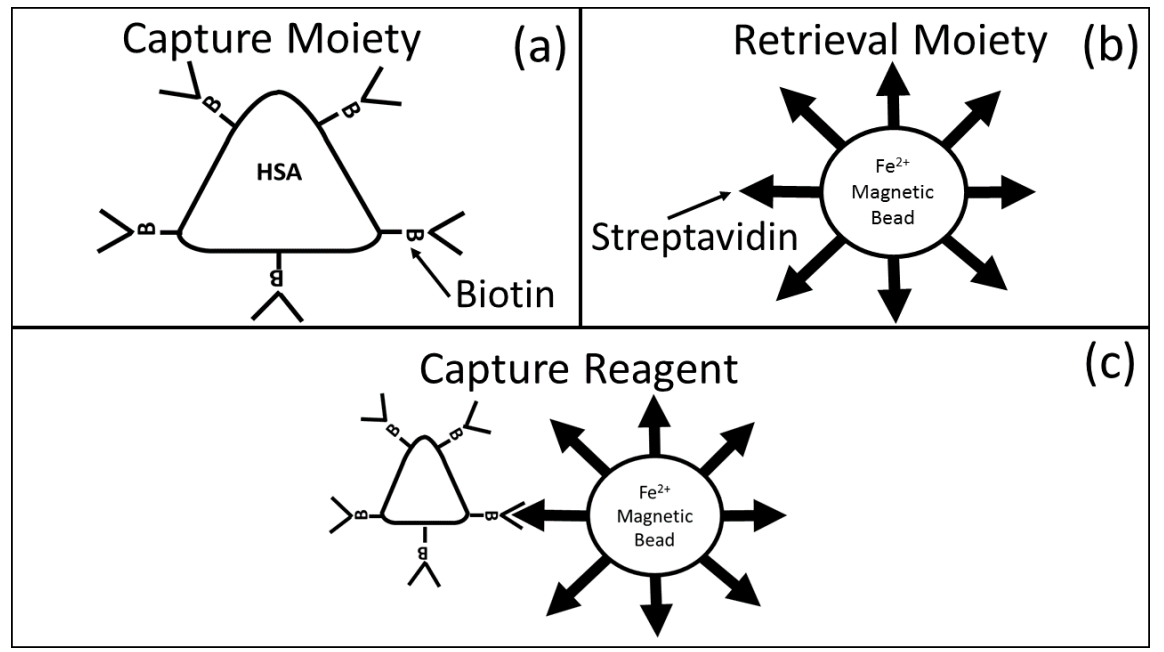

Figure 1. Components of the Capture Reagent. (a) Biotinylated HSA is the Capture Moiety. (b) Streptavidin coated magnetic beads comprise the Retrieval Moiety. (c) Biotinylated HSA and magnetic beads are coupled through the biotin-streptavidin bond forming the Capture Reagent. Of course, the precise morphology of the capture reagent is determined by the level HSA biotinylation and the standard density of streptavidin coating for the commercial magnetic beads. 
protein stability is not greatly affected by biotinylation up to a ratio of about 10:1 (biotin:HSA) [25]. Also, the biotinylated HSA species have a very similar structure to natural HSA, and therefore should have comparable ligand binding affinities. Capture experiments for capture moieties prepared at incubation ratios (biotin:HSA) of approximately 10:1, 5:1, and 1:1, suggested the intermediate coverage produced the best capture (not shown). For the capture moiety used in this study, $\mathrm{HSA}_{B}$, was prepared at an estimated coverage of 5:1.

AUC measurements concur with DSC measurements where modest levels of biotinylation do not greatly perturb overall structural stability of HSA [25]. MW determinations by AUC were found to be accurate to within $+/-5 \mathrm{kDa}$ [28]. Thus, an increase of $2.443 \mathrm{kDa}$ (corresponding to attachment of 10 biotins) $\mathrm{HSA}_{\mathrm{B}}$ would have a MW within the error of the measurement.AUC measurements indicated for $\mathrm{HSA}_{\mathrm{B}}$ at a 1:10 HSA:biotin attachment ratio a $\mathrm{MW}$ of $56.7 \mathrm{kDa}$; at a 1:5 attachment ratio $\mathrm{MW}$ of $64.6 \mathrm{kD}$ and at a 1:1 attachment ratio $\mathrm{MW}=63.3 \mathrm{kD}$. These MW values are essentially the same within the error of AUC measurements for unmodified natural HSA. For the biotinylated species monomer/dimer ratios were approximately $90 \%$ monomer, $10 \%$ dimer indicating no change in dimerization dissociation constant with increased biotinylation. Monomer frictional ratios were also quite similar indicating no differences in shape. Overall, results of AUC analysis were consistent with DSC measurements; and also indicated biotinylation of HSA does not alter gross conformation, stability, or binding capacity of the protein.

2) The Retrieval Moiety. The second component is the retrieval moiety (Figure 1(b)) comprised of streptavidin coated magnetic beads. The complete capture reagent is made by coupling the capture and retrieval moieties through the biotin-streptavidin bond (Figure 1(c)).

3) Capture Process. In the capture process, HSA-bound components are washed off the capture reagent. The wash protocol employs a mixture of weak acid and organic solvent. For DNA, high salt washes were used. With this combination of solvents the HSA-bound components are presumably washed off the capture reagent. Given the milieu of plasma molecular components and ligands such as proteins, peptide fragments, nucleic acids, fatty acids and lipids that can potentially be bound, it is not surprising diverse solvent washes might be required to dislodge bound components of various types [5] [14] [29]. The procedure for the capture process is depicted in Figure 2.

\section{Results}

Binding and Capture of Naproxen and Bromocresol Green. NAP and BCG (Sigma Aldrich) were used as received from the supplier without further purification. For these reactions $1 \mathrm{~mL}$ solutions containing $1 \mathrm{mg} / \mathrm{mL}$ human plasma and $100 \mu \mathrm{M}$ of either NAP or BCG were incubated at $4^{\circ} \mathrm{C}$ for 24 hours. Plas$\mathrm{ma} /$ ligand solutions were then added to the capture reagent and incubated an additional 24 hours at $4^{\circ} \mathrm{C}$. A magnetic field was applied and the supernatant removed. 


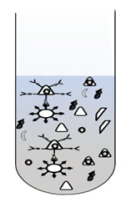

(b) Plasma and ligands with capture reagent

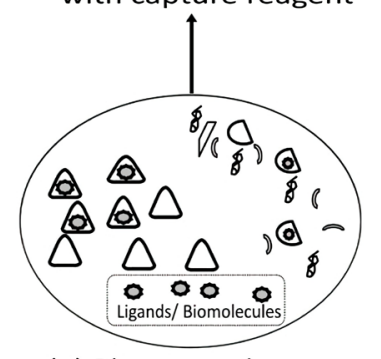

(a) Plasma and Exogenous Ligands
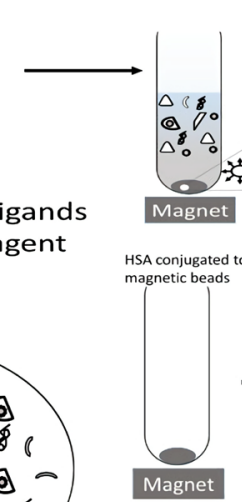

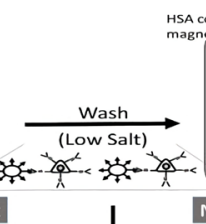

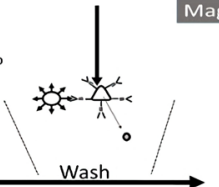
Magnet
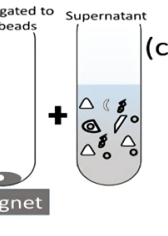

(c) Isolation Wash

.

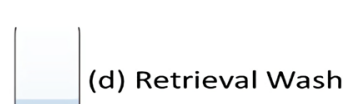

(d) Retrieval Wash

Magnet
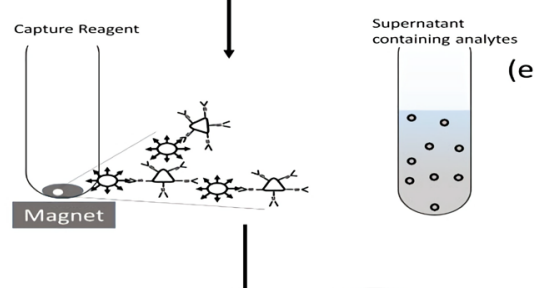

(e) Retrieval

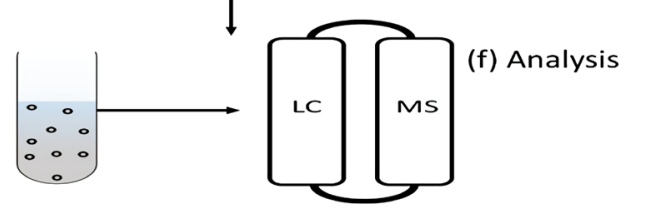

Figure 2. Summary of the capture process. The general procedure is comprised of six steps (a)-(f) as shown. (a) A plasma sample containing exogenous (and endogenous) ligands. (b) Capture reagent added to plasma sample and mixture incubated. (c) Capture reagent isolated using a magnet to pull down attached $\mathrm{HSA}_{B}$ capture moiety with (presumably) bound components. While the magnet was applied, the supernatant was withdrawn. (d) Following isolation wash, supernatant was removed, retrieval wash performed by adding a mixture of solvents intended to elute bound analytes off the capture moiety. (e) While applying magnet field, supernatant was retrieved. (f) Retrieved supernatants collected from the low (isolation) and high salt (retrieval) washes were subjected to characterization by LC/MS analysis (NAP, BCG) or gel electrophoresis (DNA).

Before retrieval of the ligands, beads were washed with $300 \mu \mathrm{L}$ of $0.1 \%$ Tween 20. The retrieval wash contained acetonitrile, acetic acid, and water in a ratio of 50:0.1:49.9 (v/v\%) with $150 \mathrm{mM} \mathrm{NaCl}$ at $\mathrm{pH}$ 3.5. The capture reagent was washed with $100 \mu \mathrm{L}$ retrieval wash solution and vortexed for 10 seconds. This was repeated, and aliquots were combined for a total volume of $200 \mu \mathrm{L}$. Results for NAP are displayed in Figure 3. The mass spectrum measured for the captured material is shown in Figure 3(a). Isotope simulation for NAP is shown Figure 3(b). As indicated by the results in Figure 3(a) component with precisely the mass of NAP was effectively captured and retrieved. The measured result shows a $-12.2 \mathrm{ppm}$ difference from theoretical. At a mass of $230 \mathrm{~m} / \mathrm{z}$, this results in a $0.28 \%$ uncertainty in identification. From comparison with a NAP sample of known concentration it was estimated from the ion count that NAP concentration in the retrieval wash was approximately $2 \mu \mathrm{M}$. Accounting for dilution of the washed sample, $400 \mathrm{nM}$ of NAP was recovered from the sample, an approximately $0.4 \%$ recovery. 


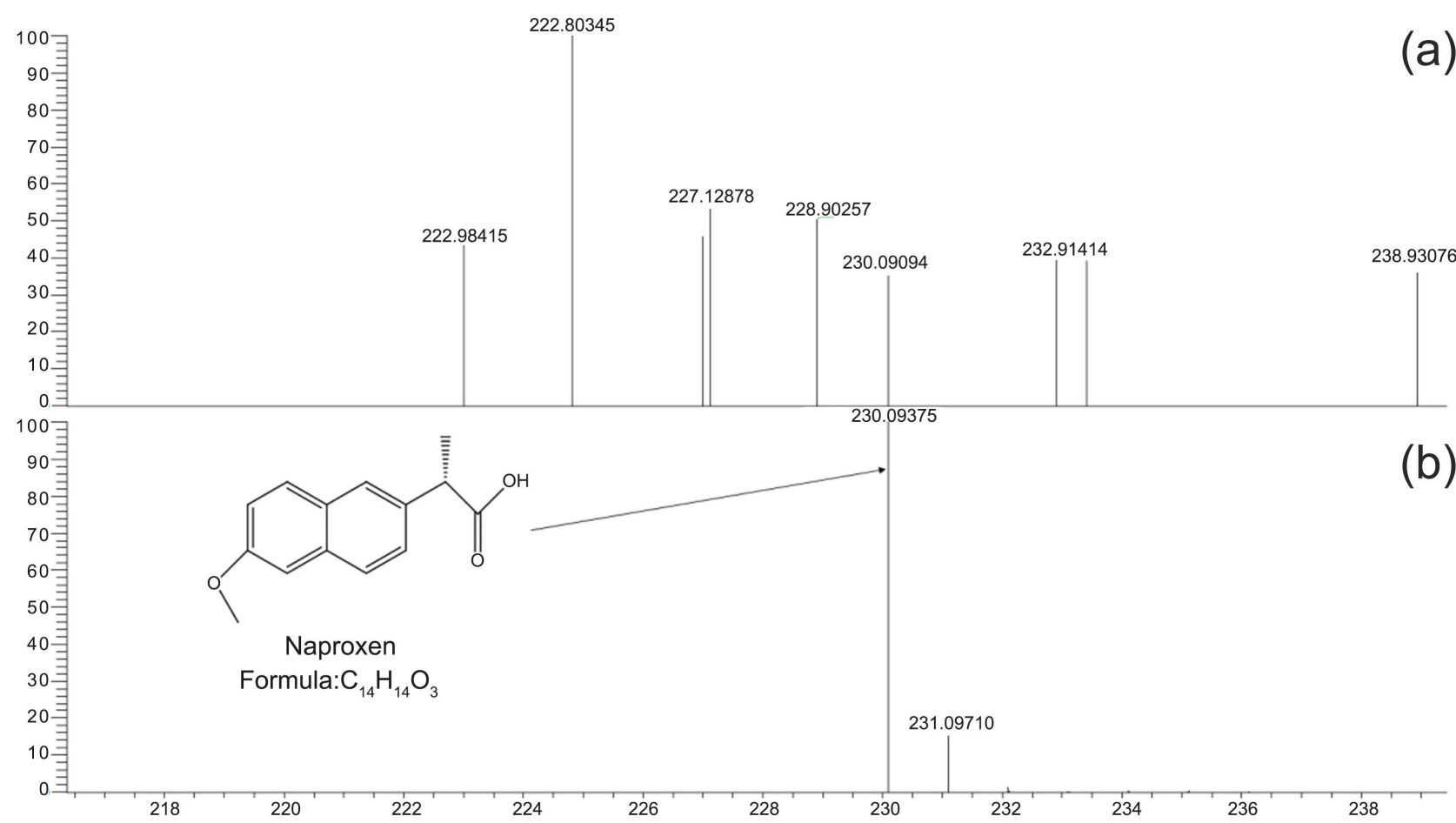

Figure 3. Mass spectrometry analysis of naproxen isolated from plasma using the capture process. (a) High resolution mass spectrum showing the presence of naproxen at $\mathrm{m} / \mathrm{z}$ 230.09094. (b) Isotope simulation for predicted naproxen peaks.

Binding and capture experiments for BCG were precisely the same as those done for NAP. The supernatant from each step was collected for further analysis. Results are shown in Figure 4; where results of LC/MS analysis in Figure 4(a) and isotope simulation in Figure 4(b) demonstrate effective retrieval of BCG. Using the primary isotope peak calculation of the measured result shows only a $2.2 \mathrm{ppm}$ difference from the theoretical $\mathrm{m} / \mathrm{z}$ for BCG. With an $\mathrm{m} / \mathrm{z}=696$, there is an approximately $0.15 \%$ uncertainty in proper identification of this molecule. Similar to NAP, the concentration of BCG in the wash solution was estimated to be 2 - $3 \mu \mathrm{M} ; 400-600 \mathrm{nM}$ was recovered from the original sample with $0.4 \%$ $0.6 \%$ recovery.

Recovery values for these experiments appear low. However based on protein coverage of the magnetic beads, there is estimated to be $417 \mathrm{nM}$ of $\mathrm{HSA}_{B}$ attached to the capture reagent available for retrieving ligands from plasma; resulting in a roughly 1:1 ratio of $\mathrm{HSA}_{\mathrm{B}}$ to retrieved ligands.

\section{Binding and capture of DNA.}

Given the multiplicity of reactive sites on HSA and its known affinity for a variety of ligands it seemed logical that HSA might also bind DNA. We chose DNA as an "unknown" test ligand and investigated HSA binding of short ssDNA and dsDNA in plasma. It turns out DNA provides an important test example for effectiveness of the capture strategy with a weakly binding ligand.

Results of analysis of DNA binding and capture are shown in Figure 5. Experiments with ssDNA were performed using $\sim 1 \mathrm{mg} / \mathrm{mL}$ low-salt solution of plasma 


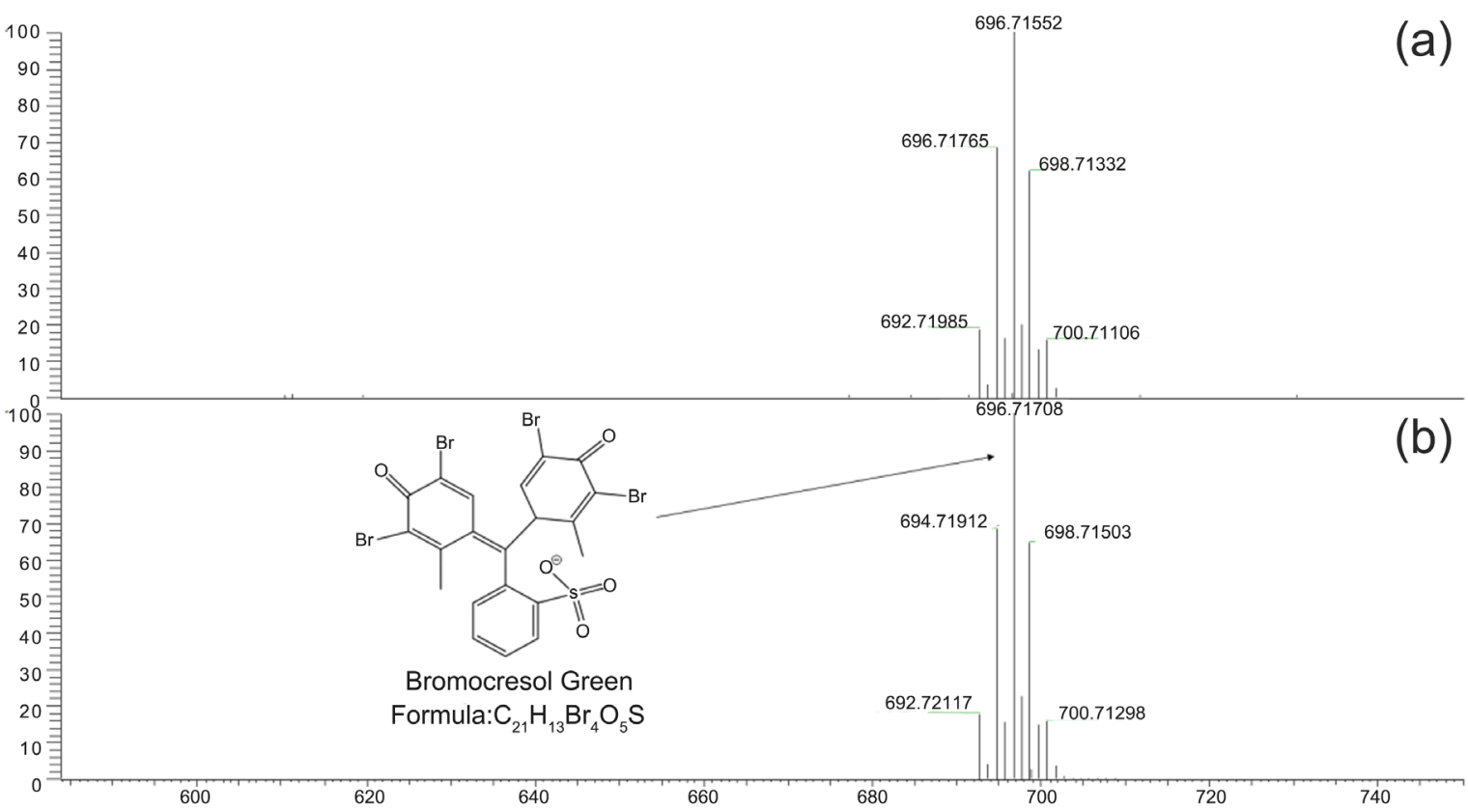

Figure 4. Mass spectrometry analysis of bromocresol green isolated from plasma using the capture process. (a) High resolution mass spectrum of captured material showing the presence of bromocresol green at $\mathrm{m} / \mathrm{z} 696.71552$. (b) Isotope simulation for predicted bromocresol green.

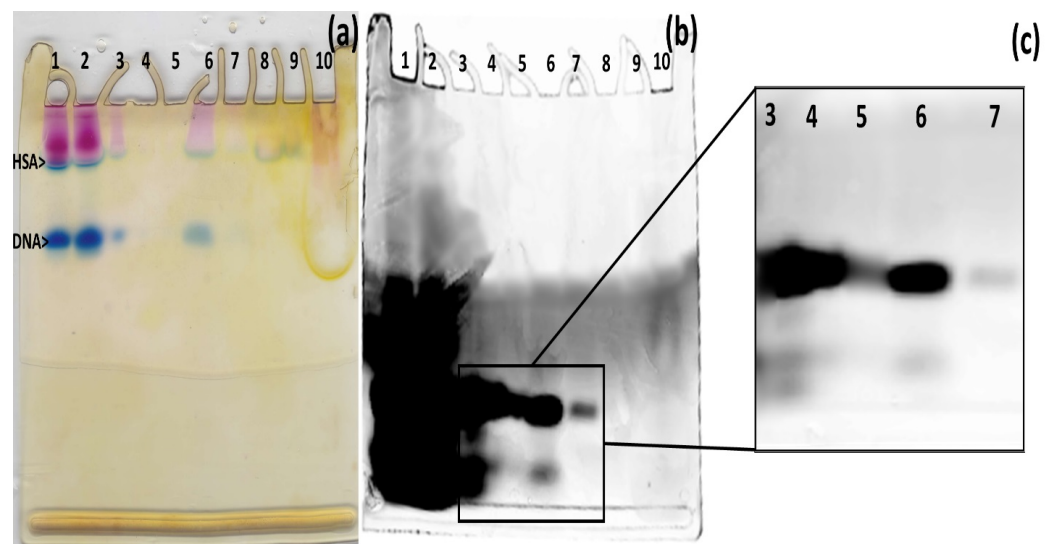

Figure 5. Gel electrophoresis analysis of DNA capture. (a) Gel results for isolated 25 base single strand DNA derived from the capture strategy. Migration positions of HSA and single strand DNA are indicated. Lane assignments are: (1) Plasma + DNA; (2) Remaining supernatant following capture reagent incubation with plasma; (3) First low salt wash; (4) Second low salt wash (5) Third low salt wash. Note, in these low salt washes after the first low salt wash there is no material present. (6) First high salt wash; (7) Second high salt wash. Note, DNA is apparently washed off with high salt; (8) HSA standard; (9) First supernatant after HSA and capture reagent incubation. (10) Biotinylated HSA cleaved from the capture reagent. (b) Gel results of isolated 25 base pair cy5-labeled double stranded DNA. Lane assignments are the same as for single strand DNA capture experiments. (c) Isolation of lanes 3 - 7, contrast correction and enhancement were performed to remove interference from the DNA standard bands in lanes $1-2$. What is notable is the decreased intensity of the DNA band in lanes 3, 4 and 5 which correspond to the low salt washes. Lane 6 and 7 are the high salt washes in which intensity of the band in lane 6 for the first high salt wash increases from lane 5 (the last low salt wash). This increase reveals that DNA was captured and isolated. 
containing $3 \mathrm{uM} 25 \mathrm{R} \mathrm{ssDNA}$ in $400 \mu \mathrm{L}$ incubated at $4^{\circ} \mathrm{C}$ for at least 24 hours. The incubated sample was added to the capture reagent and the mixture was again incubated at $4^{\circ} \mathrm{C}$ overnight. The tube containing the incubated solution sample was then placed under a magnetic field; and the capture reagent along with (presumably) bound ssDNA was pulled to the bottom of the reaction tube. The excess supernatant was removed. To isolate bound components, contents of the tube were subjected to three subsequent washes, each using $100 \mathrm{uL}$ of low-salt buffer. This was followed by two retrieval wash steps, each using $100 \mathrm{uL}$ of high-salt buffer. Supernatant fractions from all washes were collected for subsequent analysis. Results in Figure 5(a) clearly show ssDNA was effectively captured using the capture strategy and isolated with a high salt retrieval wash. This is indicated on the gel (lane 6) shown in Figure 5(a).

For binding and capture reactions with dsDNA a $\sim 1 \mathrm{mg} / \mathrm{mL}$ standard plasma low salt solution containing $33.3 \mathrm{uM}$ cy5'-25MER dsDNA in $300 \mu \mathrm{L}$ was prepared and incubated at $4^{\circ} \mathrm{C}$ for at least 24 hours. Conditions differed slightly from those for ssDNA. Since under similar conditions dsDNA appeared to be a relatively weaker binder, and more difficult to visualize, a higher concentration of hot-labeled duplex DNA was employed. Incubated plasma/DNA solutions were subjected to capture procedures carried out in similar fashion as described above for ssDNA. Results are shown in Figure 5(b) where evidently a slight amount of bound dsDNA was effectively captured and washed off the reagent. In summary, gel analysis indicated ssDNA and dsDNA binding to HSA was detectable, but weak.

Thermogram analysis of mixtures of plasma and HSA with different ligands

Naproxen: Thermograms ( $\Delta \mathrm{Cp}$ versus $\mathrm{T}$ ) of mixtures of plasma and NAP are shown in Figure 6(a). Concentrations for these experiments were $1 \mathrm{mg} / \mathrm{mL}$ of plasma with NAP at $100 \mu \mathrm{M}$. Clearly, the presence of NAP perturbs the plasma thermogram, shifting the curve to higher temperatures $\left(\sim 5^{\circ} \mathrm{C}\right)$. The shift of the plasma thermograms due to NAP apparently has much to do with binding of NAP to HSA in plasma. This is demonstrated by the effect of NAP on the HSA thermogram shown in Figure 6(b). In these experiments HSA was present at 2 $\mathrm{mg} / \mathrm{mL}(28 \mu \mathrm{M})$ and NAP at $100 \mu \mathrm{M}$. The thermogram for the HSA/NAP mixture was approximately the same intensity and shifted up by $\sim 5^{\circ} \mathrm{C}$. Separate DSC experiments for HSA at the same concentration in different mixtures with greater concentrations than $100 \mu \mathrm{M}$ of NAP indicated saturation was not obtained at $100 \mu \mathrm{M}$ (not shown). Thus, there is not expected to be an excess of free NAP in these mixtures. Effects of NAP on the thermogram of HSA are clear; at this concentration of NAP $(100 \mu \mathrm{M})$ the HSA thermogram is shifted to higher temperature $\left(5^{\circ} \mathrm{C}\right)$, with $\Delta \mathrm{H}_{\text {cal }}=181.7 \mathrm{kcal} / \mathrm{mol}$ for the HSA/ligand mixture compared to $155.0 \mathrm{kcal} / \mathrm{mol}$ for HSA alone. This measured value of standard HSA was within expected error of previously published results [25].

Bromocresol green: Under similar conditions, $1 \mathrm{mg} / \mathrm{mL}$ plasma and $100 \mu \mathrm{M}$ 

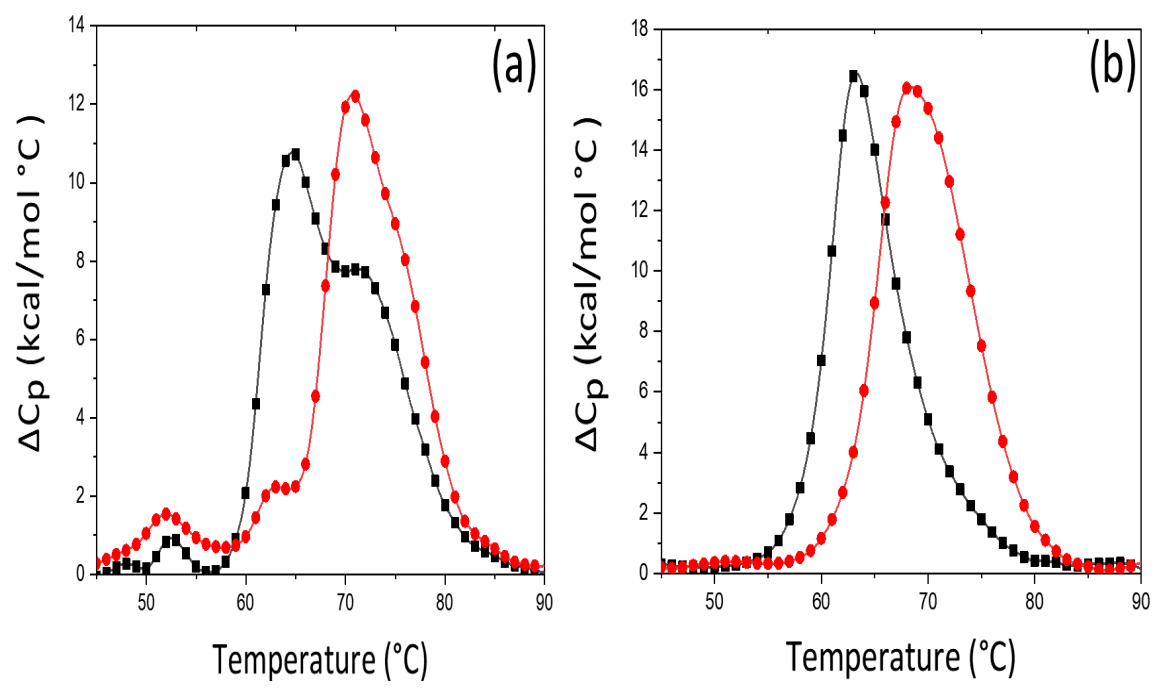

Figure 6. Thermograms of plasma and HSA in mixtures with naproxen. (a) Thermograms of whole plasma (-) plasma and NAP mixture $(\bullet)$. Clearly the plasma thermogram of the mixture is shifted up in temperature in the presence of NAP compared to the thermogram of plasma alone. (b) Thermograms of HSA ( $)$ and the HSA and NAP mixture $(\bullet)$. Again, the thermogram of the mixture is shifted up in temperature.

BCG, the thermogram ( $\triangle \mathrm{Cp}$ versus $\mathrm{T}$ ) for the mixture of BCG and plasma (shown in Figure $7(\mathrm{a})$ ), is shifted to higher temperature $\sim 7^{\circ} \mathrm{C}$ compared to the plasma thermogram. This is quite similar to effects of NAP. Since BCG is known to bind HSA, effects of BCG binding on the plasma thermogram seen in Figure 7(a) are also surely because the ligand binds HSA in plasma and thereby alters the plasma thermogram. In concurrence, the thermogram of HSA at $2 \mathrm{mg} / \mathrm{mL}$ in a mixture with $100 \mu \mathrm{M}$ BCG, shown in Figure 7(b), indicates a similar effect of BCG. The thermogram for the HSA mixture with BCG is approximately $20 \%$ lower in intensity, a little broader and shifted up in temperature by $\sim 7^{\circ} \mathrm{C}$ compared to the thermogram of HSA alone. The calorimetric enthalpy is $\Delta \mathrm{H}_{\mathrm{cal}}=165.6 \mathrm{kcal} / \mathrm{mol}$ for the HSA/ligand and only slightly higher than HSA alone.

\section{DNA}

For mixtures of DNA with plasma or $\mathrm{HSA}_{B}$ it was necessary to explore origins of the perturbed thermogram and verify that what was captured was actually responsible for the observed disturbance of the thermogram. This required knowledge of whether the mere presence of the ligand and/or significant binding of the ligand (in this case dsDNA) to HSA was responsible for observed perturbed thermograms of plasma and $\mathrm{HSA}_{B}$ in mixtures with DNA. Thus, it was necessary to dissect thermograms of the DNA/plasma and DNA/HSA $\mathrm{B}_{\mathrm{B}}$ mixtures.

Analysis of thermograms of mixtures of plasma with NAP or BCG presented no problems since the ligands themselves have an essentially insignificant $\Delta \mathrm{Cp}$ over the temperature range of the plasma thermogram (not shown). However, the case is different for mixtures of plasma or HSA with either ssDNA or dsDNA because both ssDNA and dsDNA individually display a very significant $\triangle \mathrm{Cp}$ over the temperature range of the plasma thermogram. In the case of DNA, a 

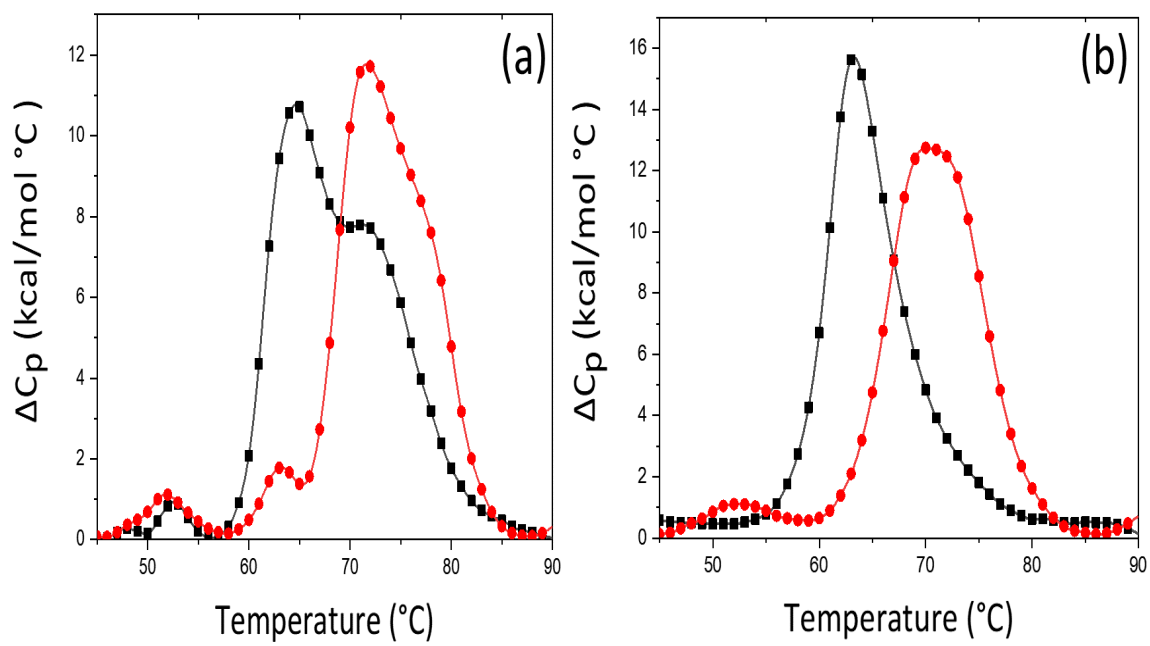

Figure 7. Thermograms of plasma and HSA in mixtures with bromocresol green. (a) Thermograms of whole plasma (•) plasma and BCG mixture $(\bullet)$. Clearly the plasma thermogram of the mixture is shifted up in temperature in the presence of BCG compared to the thermogram of plasma alone. (b) Thermograms of HSA (-) and the HSA and BCG mixture $(\bullet)$. Again, the thermogram of the mixture is shifted up in temperature.

direct comparison of the $\mu \mathrm{W}$ versus $\mathrm{T}$ curves was preferable. The analysis was required to determine whether thermograms measured for mixtures of plasma or $\mathrm{HSA}_{\mathrm{B}}$ with DNA were equivalent to the calculated composite curves constructed from the numerical sums of thermograms for the individual components i.e. plasma or HSA and DNA. Essentially, identical measured and calculated composite curves reveal there is little effect of the "interaction" of DNA with plasma or $\mathrm{HSA}_{\mathrm{B}}$. At least the interaction is not significant enough to affect the plasma or $\mathrm{HSA}_{B}$ thermogram.

Baseline corrected $\mu \mathrm{W}$ versus $\mathrm{T}$ thermograms for the individual components and the measured composite curves of mixtures of plasma and $\mathrm{HSA}_{\mathrm{B}}$ with ssDNA and dsDNA are shown and compared in Figure 8 and Figure 9. Calculated composite curves were constructed from individual curves using a linear combination of the respective thermograms of the individual components, measured at exactly the same concentrations as in the mixtures. Experimentally measured composite curves were normalized to the $\mu \mathrm{W}$ versus $\mathrm{T}$ thermogram for $\mathrm{HSA}_{\mathrm{B}}$ alone.

\section{Single Strand DNA}

Thermograms ( $\mu \mathrm{W}$ versus T plots) for plasma and DNA alone and their mixtures are shown in Figure 8. Those for ssDNA and plasma are shown in Figure 8 (a). The thermogram for ssDNA alone displays a small $\Delta \mathrm{Cp}$ that spans the early low temperature region $\left(45^{\circ} \mathrm{C}-75^{\circ} \mathrm{C}\right)$ of the plasma thermogram. Results of independent experiments with the ssDNA alone and energetic analysis of the sequence (not shown) suggested this transition likely corresponds to melting of a relatively stable intramolecular hairpin loop structure that forms in the short ssDNA oligomer. Displayed in Figure 8(b), are the measured thermograms for the ssDNA/plasma mixture and composite thermogram calculated from the sum 

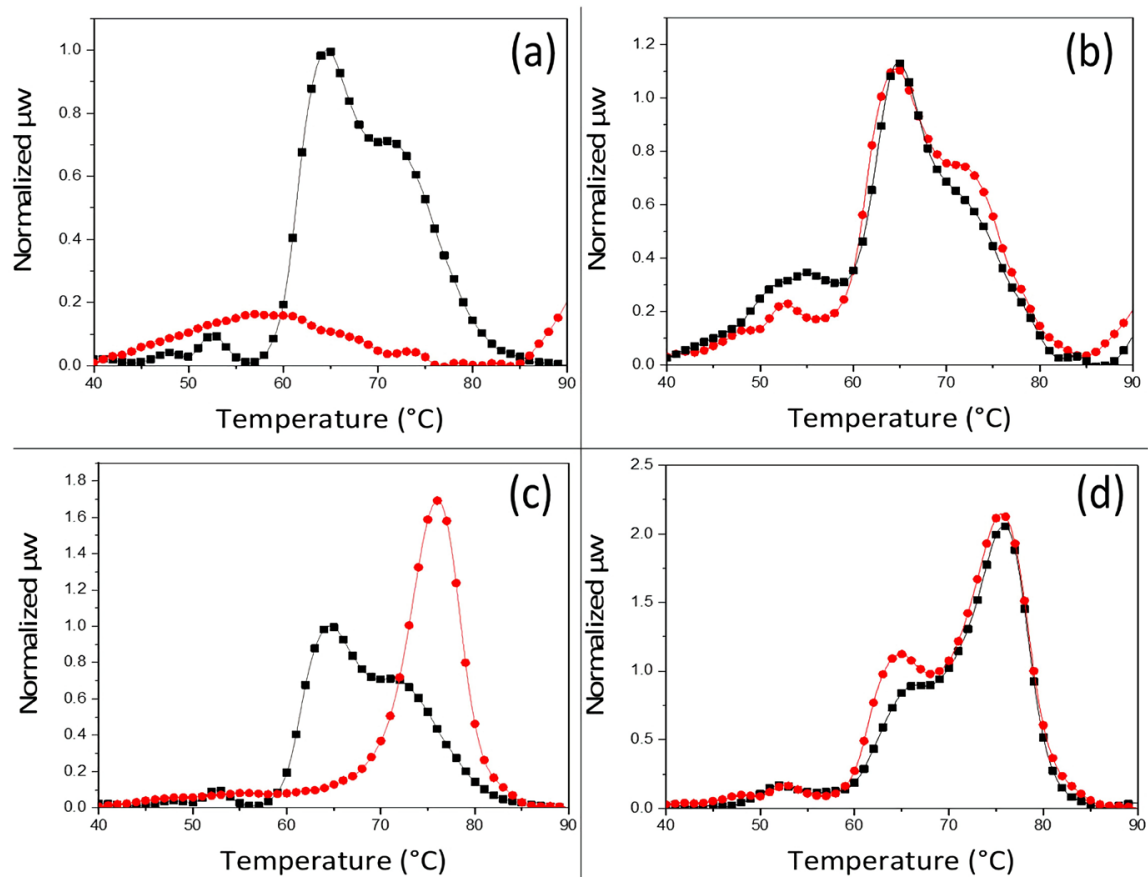

Figure 8. Thermograms of plasma in mixtures with single strand and double stranded DNA. (a) Thermograms of plasma alone ( $\bullet$ ) and the 25 base ssDNA alone (•). (b) Thermograms of the plasma and ssDNA mixtures; (-) Measured thermogram of plasma and ssDNA; (•) Thermogram calculated from the sum of the individual thermograms of plasma and ssDNA in (a). (c) Thermograms of plasma alone ( $\bullet$ ) and the 25 base pair dsDNA alone (•). (d) Thermograms of plasma and dsDNA mixtures; (•) Measured thermogram of plasma and dsDNA; $(\bullet)$ Composite thermogram calculated from the sum of the individual thermograms of plasma and dsDNA in (c). All curves were normalized to the thermogram of plasma alone.

of the individual thermograms. Two notable observations emerge from the comparison in Figure 8(b). The thermogram for the plasma/ssDNA mixture is not very different from the plasma thermogram alone in Figure 8(a) and; the calculated composite thermogram in Figure $8(\mathrm{~b})$ is also very close to the measured composite thermogram with only very minor differences. It is tempting to equate these small differences to low level interactions of ssDNA with plasma. If such an interaction does exist, it does not involve substantial changes in thermodynamic stability sufficient to significantly affect the plasma thermogram. Thermograms for ssDNA and $\mathrm{HSA}_{B}$ alone are shown in Figure 9(a). Measured and calculated composite curves, just as determined for plasma and ssDNA (Figure 8(b)), are shown in Figure 9(b). Again, there are only small differences between measured and calculated composite curves for the mixtures.

Measured and calculated thermograms for mixtures of plasma and ssDNA are nearly quantitatively identical with only minor differences around $48^{\circ} \mathrm{C}-60^{\circ} \mathrm{C}$ and $70^{\circ} \mathrm{C}-77^{\circ} \mathrm{C}$. The major peak on plasma thermograms at $\sim 65^{\circ} \mathrm{C}$ is attributed primarily to $\mathrm{HSA}_{\mathrm{B}}$. The much smaller peak around $53^{\circ} \mathrm{C}$ has been attributed to melting of fibrinogen [30] [31] [32] [33]. Since the influence of ssDNA alone has been subtracted out, this higher peak seen at $53^{\circ} \mathrm{C}$ could be due to ssDNA 

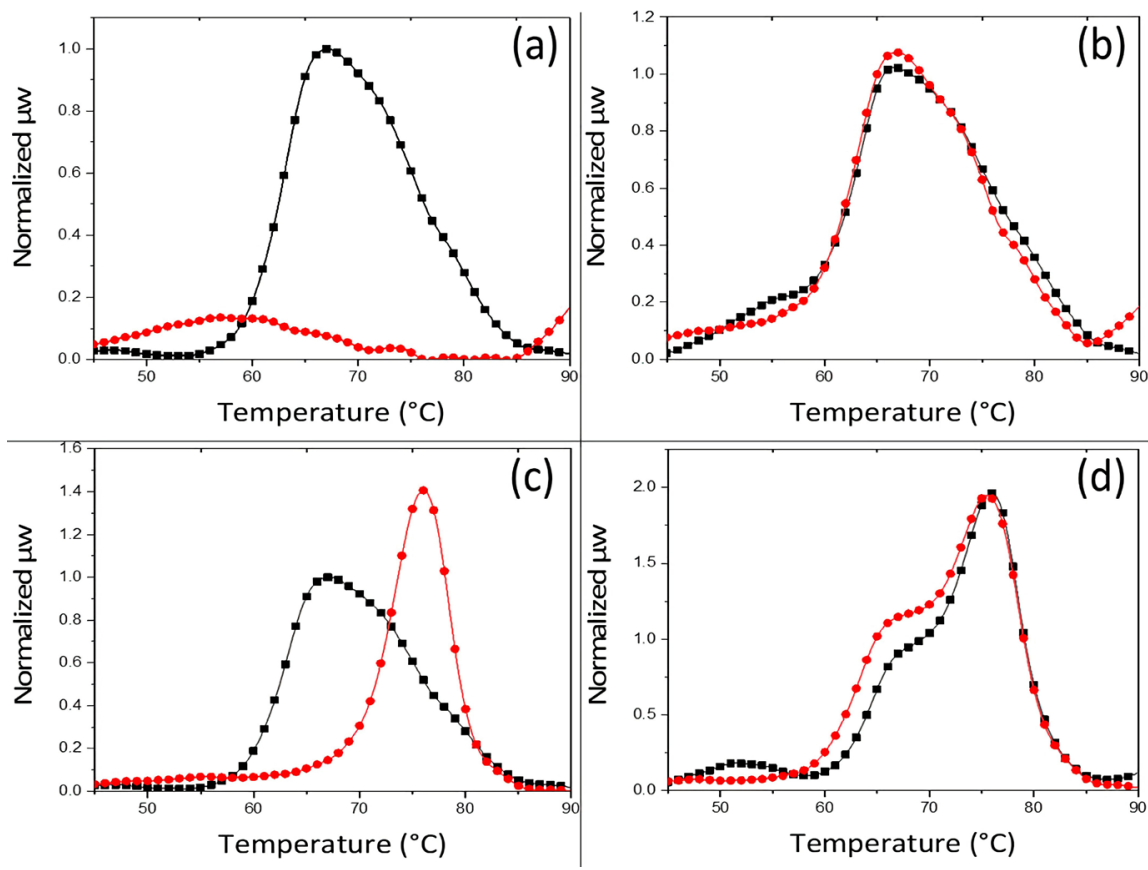

Figure 9. Thermograms of $\mathrm{HSA}_{\mathrm{B}}$ in mixtures with single strand and double stranded DNA. (a) Thermograms of $\mathrm{HSA}_{B}$ alone $(\bullet)$ and the 25 base pair ssDNA alone ( $\bullet$ ). (b) Thermograms of the $\mathrm{HSA}_{\mathrm{B}}$ and ssDNA mixtures; (-) Measured thermogram of $\mathrm{HSA}_{\mathrm{B}}$ and ssDNA; (•) Thermogram calculated from the sum of the individual thermograms of $\mathrm{HSA}_{B}$ and ssDNA in (a). (c)Thermograms of HSA $\mathrm{H}_{\mathrm{B}}$ alone $(\boldsymbol{\bullet})$ and the 25 base dsDNA alone $(\bullet)$. (d) Thermograms of $\mathrm{HSA}_{\mathrm{B}}$ and dsDNA; (•) Measured thermogram of $\mathrm{HSA}_{\mathrm{B}}$ and dsDNA; $(\bullet)$ Composite thermogram calculated from the sum of the individual thermograms of $\mathrm{HSA}_{B}$ and dsDNA in (c). All curves were normalized to the thermogram of $\mathrm{HSA}_{\mathrm{B}}$ alone.

interactions with fibrinogen in plasma, but this remains speculative until verification. Regarding the slight difference at $\sim 65^{\circ} \mathrm{C}$, this region of the plasma thermogram primarily corresponds to melting of immunoglobulins such as IgG and IgA, and may reveal interactions of them with ssDNA.

\section{Double Strand DNA}

Thermograms of dsDNA and plasma alone are shown in Figure 8(c). Unlike ssDNA, dsDNA displays a significant melting transition that overshadows much of the high temperature region $\left(65^{\circ} \mathrm{C}-85^{\circ} \mathrm{C}\right)$ of the plasma thermogram. Given that the curves are normalized to the plasma thermogram, apparently under these conditions the DNA has a relatively larger $\Delta \mathrm{Cp}$ compared to plasma. Measured and constructed composite curves are shown in Figure 8(d). Just as seen for ssDNA, calculated composite curves for dsDNA constructed from the sum of the individual thermograms of plasma and dsDNA (measured under precisely the same conditions as in plasma mixtures) were not greatly different. Also consistent with weak, inconsequential (in the thermodynamic sense) binding of dsDNA to HSA, there is a small difference from approximately $60^{\circ} \mathrm{C}$ $70^{\circ} \mathrm{C}$ which corresponds to the $\mathrm{HSA}_{\mathrm{B}}$ transition region suggesting perhaps a small contribution from $\mathrm{HSA}_{\mathrm{B}} / \mathrm{dsDNA}$ interactions. Thermograms of dsDNA 
and $\mathrm{HSA}_{\mathrm{B}}$ alone are shown in Figure 9(c). The measured and calculated composite curves constructed from the individual thermograms measured under the same conditions are shown in Figure 9(d).

Measured composite curves versus calculated constructed composites in Figure 8(d) and Figure 9(d) show for both ssDNA and dsDNA, with the minor differences stated above, there is little variation over the entire temperature range. Thus, indicating these ligands interact very weakly in the sense of having an insignificant effect on the thermogram.

NAP and BCG are known to bind HSA and this activity clearly manifests on thermograms of mixtures of the ligands with plasma. Heretofore, binding activity of HSA with ssDNA or dsDNA has not (to our knowledge) been reported. Results showed that although thermograms of plasma alone and mixtures of plasma with DNA were very different, after proper analysis little evidence for binding was actually obtained. Captured DNA (presumably previously associated with HSA in plasma) was detected on gels. From results of independent gel experiments, binding could be detected with an estimated binding constant less than mM. For a binding constant in the micromolar range, it is expected that HSA would be $50 \%$ saturated with DNA; this binding should be easily detectable by AUC. Weak binding of DNA to $\mathrm{HSA}_{\mathrm{B}}$ is consistent with lack of binding results in AUC experiments, implying that the DNA concentration is at least 100-fold lower than the binding constant.

Despite low binding activity of ssDNA and dsDNA to plasma, DNA is an ideal example ligand for several reasons. DNA is not really an exogenous ligand per se as similar molecules could actually be encountered endogenously. In this regard DNA is an example of an actual unknown analyte with relatively weak binding to HSA. Experiments with DNA provided a practical test of the efficacy of the capture strategy on such an unknown analyte in plasma. Analysis of DNA plasma thermograms revealed special considerations that must be taken into account for proper analysis of thermograms of the mixtures.

\section{Discussion}

Results demonstrate the ability and application of the capture strategy to isolate from plasma four different types of ligands, two of which NAP and BCG are well-known HSA binders; and short ssDNA and dsDNAs (25 nucleotides, 25 base pairs, respectively), not known to have significant HSA binding activity. In individual experiments these ligands were added to plasma and subjected to the capture scheme. Captured products were analyzed by MS or gel electrophoresis. First and foremost, results reveal that binding occurred as demonstrated by effective capture of added ligands. Mixtures of the different ligands with plasma and HSA were also subjected to DSC analysis. Individual thermograms of plasma (w/o ligands), HSA, and biotinylated HSA ( $\mathrm{HSA}_{\mathrm{B}}$ ) provided an analytical basis set of thermograms enabling comparison and characterization of measured thermograms of the plasma/ligand mixtures. This was an essential requirement 
since in all cases plasma/ligand thermograms were different than that of plasma alone.

Applications of Thermogram Analysis in Diagnostics: DSC has been employed for many years as the method of choice for quantitative thermodynamic studies of protein and DNA denaturation [34]-[39]. In DSC experiments excess heat capacity of thermally induced unfolding of proteins is directly measured and provides evaluation of the calorimetric enthalpy, $\Delta \mathrm{H}_{\mathrm{cal}}$ [31] [40] [41].

Over the past decade, applications of DSC in the realm of proteomic diagnostics have been reported [1] [14] [15] [20] [42] [43] [44]. Reportedly, the primary basis for diagnostic applications lies in observations for a number of diseased states that plasma thermograms are systematically and statistically different from the average normal plasma thermogram. Diseased states and stages can manifest as specifically distinct patterns on thermograms. Based on these observations robust statistical analysis has demonstrated utility of plasma thermogram analysis for disease monitoring and response to therapy [19] [22] [30] [45] [46].

It would seem these observations make compelling arguments for the potential power of DSC analysis in diagnostic applications. Unfortunately, that potential diagnostic power has not been realized due to difficulties in identifying specific components of diseased plasma responsible for the observed disease-specific perturbed patterns on plasma thermograms. There is lack of understanding of the precise mechanism underlying observed perturbations of plasma thermograms which provokes the lingering essential question: What disease specific entities in plasma cause the thermogram shifts? An operative hypothesis has been that in diseased states, endogenous low molecular weight proteins, peptide fragments, lipids and circulating nucleic acids (generally referred to as analytes or ligands) characteristic of that disease (and therefore indicative of its presence), increase in concentration in diseased plasma [5] [14] [15] [47]. The prevailing opinion is that such analytes form complexes with the most abundant proteins in plasma (specifically HSA and immunoglobulins). These interactions alter thermodynamic stabilities of the proteins they bind, which in turn affects the recorded plasma thermograms. But little actual proof of this has been reported.

Our major contention is that most significant perturbations of plasma thermograms, brought on by ligand binding, can primarily be attributed to interactions with HSA. These interactions affect HSA thermodynamic stability which is directly reflected in the plasma thermogram. Perturbations of the plasma thermograms arise from thermodynamically significant interactions between circulating analytes and the most prominent plasma proteins, primarily HSA. These effects manifest on plasma thermograms producing characteristic patterns for specific diseases that differ from the average "normal" signature [12] [16]-[24] [26] [30] [31] [32] [33] [40] [41] [45] [46] [48]-[66]. In this way, plasma thermograms can be more sensitive to binding interactions than standard techniques such as electrophoresis and mass spectrometry. Changes in plasma thermograms resulting from binding (for example) of small peptides to a larger receptor are 
far more dramatic than changes in either mass or charge associated with the binding event.

Although DSC thermograms can be highly sensitive to binding interactions, thermograms themselves are mere indicators of binding presence and provide, on their own, little insight into actual identities of the specific binding ligands involved. Thermogram analysis in combination with the capture strategy provides a direct, fast, and simple means to quantitatively validate the aforementioned operative hypothesis by providing the link between causative agents circulating in blood that bind to plasma proteins, and specific perturbations of plasma thermograms. Using the capture strategy, likely candidates can be isolated from plasma and their effects on the HSA thermogram independently assessed. By identifying circulating ligands in plasma specifically responsible, the capture approach provides a novel means to begin to unravel features of the molecular mechanism(s) underlying observed specific DSC plasma thermogram patterns, and their association with human disease.

\section{Conclusions}

Results of this study more clearly define, from a physical perspective features associated with the general mechanism responsible for perturbations of plasma thermograms associated with ligand interactions. As results clearly show for thermograms of mixtures of plasma or HSA with the same HSA-binding ligands are significantly different than thermograms of plasma or HSA alone. Up to this point, there have been no reports demonstrating, as we have done here, effects of specific ligands on plasma thermograms and the ability to retrieve the ligands from plasma.

With further development, the capture strategy may become an invaluable biomarker discovery and proteomics analysis screening tool. Using this strategy will enable classification of important ligands, based on their associated perturbations of the plasma thermogram. With sufficient training sets of data, the process could be used to provide relevant characterizations of captured ligands and classification of their type and character based on their specific effects on plasma thermograms alone. Once this is accomplished the true diagnostic power of this method can be realized.

\section{Acknowledgements}

This work was supported in part by a faculty enhancement award to Professor Albert S. Benight from Portland State University.

\section{Conflicts of Interest}

The authors declare no conflicts of interest regarding the publication of this paper.

\section{References}

[1] Anderson, N.L., Polanski, M., Pieper, R., Gatlin, T., Tirumalai, R.S., Conrads, T.P., 
Veenstra, T.D., Adkins, J.N., Pounds, J.G., Fagan, R. and Lobley, A. (2004) The Human Plasma Proteome: A Nonredundant List Developed by Combination of Four Separate Sources. Molecular \& Cellular Proteomics, 3, 311-326. https://doi.org/10.1074/mcp.M300127-MCP200

[2] Yamasaki, K., Chuang, V.T.G., Maruyama, T. and Otagiri, M. (2013) Albumin-Drug Interaction and Its Clinical Implication. Biochimica et Biophysica Acta (BBA) General Subjects, 1830, 5435-5443.

https://doi.org/10.1016/j.bbagen.2013.05.005

[3] Dennis, M.S., Zhang, M., Meng, Y.G., Kadkhodayan, M., Kirchhofer, D., Combs, D. and Damico, L.A. (2002) Albumin Binding as a General Strategy for Improving the Pharmacokinetics of Proteins. Journal of Biological Chemistry, 277, 35035-35043. https://doi.org/10.1074/jbc.M205854200

[4] Peters Jr., T. (1995) All about Albumin: Biochemistry, Genetics, and Medical Applications. Academic Press, Cambridge. https://doi.org/10.1016/B978-012552110-9/50006-4

[5] Zhou, M., Lucas, D.A., Chan, K.C., Issaq, H.J., Petricoin, E.F., Liotta, L.A., Veenstra, T.D. and Conrads, T.P. (2004) An Investigation into the Human Serum "Interactome". Electrophoresis, 25, 1289-1298. https://doi.org/10.1002/elps.200405866

[6] Abou-Zied, O.K. and Al-Lawatia, N. (2011) Exploring the Drug-Binding Site Sudlow I of Human Serum Albumin: The Role of Water and Trp214 in Molecular Recognition and Ligand Binding. ChemPhysChem, 12, 270-274. https://doi.org/10.1002/cphc.201000742

[7] McFarland, C.D., De Filippis, C., Jenkins, M., Tunstell, A., Rhodes, N.P., Williams, D.F. and Steele, J.G. (1998) Albumin-Binding Surfaces: In Vitro Activity. Journal of Biomaterials Science, Polymer Edition, 9, 1227-1239. https://doi.org/10.1163/156856298X00749

[8] Sudlow, G., Birkett, D. and Wade, D. (1976) Further Characterization of Specific Drug Binding Sites on Human Serum Albumin. Molecular Pharmacology, 12, 1052-1061.

[9] Fasano, M., Curry, S., Terreno, E., Galliano, M., Fanali, G., Narciso, P., Notari, S. and Ascenzi, P. (2005) The Extraordinary Ligand Binding Properties of Human Serum Albumin. IUBMB Life, 57, 787-796. https://doi.org/10.1080/15216540500404093

[10] Joseph, K.S., Moser, A.C., Basiaga, S.B.G., Schiel, J.E. and Hage, D.S. (2009) Evaluation of Alternatives to Warfarin as Probes for Sudlow Site I of Human Serum Albumin: Characterization by High-Performance Affinity Chromatography. Journal of Chromatography $A, 1216,3492-3500$.

https://doi.org/10.1016/j.chroma.2008.09.080

[11] O’Connell, T.X., Horita, T.J. and Kasravi, B. (2005) Understanding and Interpreting Serum Protein Electrophoresis. American Family Physician, 71, 105-112.

[12] Garbett, N.C. and Chaires, J.B. (2012) Thermodynamic Studies for Drug Design and Screening. Expert Opinion on Drug Discovery, 7, 299-314. https://doi.org/10.1517/17460441.2012.666235

[13] Simard, J.R., Zunszain, P.A., Hamilton, J.A. and Curry, S. (2006) Location of High and Low Affinity Fatty Acid Binding Sites on Human Serum Albumin Revealed by NMR Drug-Competition Analysis. Journal of Molecular Biology, 361, 336-351. https://doi.org/10.1016/j.jmb.2006.06.028

[14] Geyer, P.E., Holdt, L.M., Teupser, D. and Mann, M. (2017) Revisiting Biomarker Discovery by Plasma Proteomics. Molecular Systems Biology, 13, 942. 
https://doi.org/10.15252/msb.20156297

[15] Geyer, P.E., Kulak, N.A., Pichler, G., Holdt, L.M., Teupser, D. and Mann, M. (2016) Plasma Proteome Profiling to Assess Human Health and Disease. Cell Systems, 2, 185-195. https://doi.org/10.1016/j.cels.2016.02.015

[16] Ferencz, A. and Lörinczy, D. (2017) DSC Measurements of Blood Plasma on Patients with Chronic Pancreatitis and Operable and Inoperable Pancreatic Adenocarcinoma. Journal of Thermal Analysis and Calorimetry, 127, 1187-1192. https://doi.org/10.1007/s10973-016-5371-4

[17] Michnik, A., Sadowska-Krępa, E., Domaszewski, P., Duch, K. and Pokora, I. (2017) Blood Serum DSC Analysis of Well-Trained Men Response to CrossFit Training and Green Tea Extract Supplementation. Journal of Thermal Analysis and Calorimetry, 130, 1253-1262. https://doi.org/10.1007/s10973-017-6346-9

[18] Szalai, Z., Molnár, T.F. and Lörinczy, D. (2017) Role of Differential Scanning Calorimetry (DSC) in the Staging of COPD. Journal of Thermal Analysis and Calorimetry, 127, 1231-1238. https://doi.org/10.1007/s10973-016-5495-6

[19] Kendrick, S.K., Zheng, Q., Garbett, N.C. and Brock, G.N. (2017) Application and Interpretation of Functional Data Analysis Techniques to Differential Scanning Calorimetry Data from Lupus Patients. PLOS ONE, 12, e0186232. https://doi.org/10.1371/journal.pone.0186232

[20] Kim, N.A., Jin, J.H., Kim, K.H., Lim, D.G., Cheong, H., Kim, Y.H., Ju, W., Kim, S.C. and Jeong, S.H. (2016) Investigation of Early and Advanced Stages in Ovarian Cancer Using Human Plasma by Differential Scanning Calorimetry and Mass Spectrometry. Archives of Pharmacal Research, 39, 668-676.

https://doi.org/10.1007/s12272-016-0722-Z

[21] Brudar, S., Černigoj, U., Podgornik, H., Kržan, M. and Prislan, I. (2017) Use of Differential Scanning Calorimetry and Immunoaffinity Chromatography to Identify Disease Induced Changes in Human Blood Plasma Proteome. Acta Chimica Slovenica, 64, 564-570. https://doi.org/10.17344/acsi.2016.2970

[22] Garbett, N.C., Mekmaysy, C.S., DeLeeuw, L. and Chaires, J.B. (2015) Clinical Application of Plasma Thermograms. Utility, Practical Approaches and Considerations. Methods, 76, 41-50. https://doi.org/10.1016/j.ymeth.2014.10.030

[23] Moezzi, M., Ferencz, A. and Lörinczy, D. (2014) Evaluation of Blood Plasma Changes by Differential Scanning Calorimetry in Psoriatic Patients Treated with Drugs. Journal of Thermal Analysis and Calorimetry, 116, 557-562. https://doi.org/10.1007/s10973-013-3585-2

[24] Todinova, S., Krumova, S., Kurtev, P., Dimitrov, V., Djongov, L., Dudunkov, Z. and Taneva, S.G. (2012) Calorimetry-Based Profiling of Blood Plasma from Colorectal Cancer Patients. Biochimica et Biophysica Acta, 1820, 1879-1885.

https://doi.org/10.1016/j.bbagen.2012.08.001

[25] Hoang, H., Manyanga, F., Morakinyo, M.K., Pinkert, V., Sarwary, F., Fish, D.J., Brewood, G.P. and Benight, A.S. (2016) Effects of Selective Biotinylation on the Thermodynamic Stability of Human Serum Albumin. Journal of Biophysical Chemistry, 7, 9. https://doi.org/10.4236/jbpc.2016.71002

[26] Garbett, N.C., Mekmaysy, C.S. and Chaires, J.B. (2010) Sedimentation Velocity Ultracentrifugation Analysis for Hydrodynamic Characterization of G-Quadruplex Structures. Methods in Molecular Biology, 608, 97-120. https://doi.org/10.1007/978-1-59745-363-9 7

[27] Cölfen, H., Laue, T.M., Wohlleben, W., Schilling, K., Karabudak, E., Langhorst, B.W., Brookes, E., Dubbs, B., Zollars, D., Rocco, M. and Demeler, B.J.E.B.J. (2010) 
The Open AUC Project. European Biophysics Journal with Biophysics Letters, 39, 347-359. https://doi.org/10.1007/s00249-009-0438-9

[28] Zhao, H., Ghirlando, R., Alfonso, C., Arisaka, F., Attali, I., Bain, D.L., Bakhtina, M.M., Becker, D.F., Bedwell, G.J. and Bekdemir, A. (2015) A Multilaboratory Comparison of Calibration Accuracy and the Performance of External References in Analytical Ultracentrifugation. PLoS ONE, 10, e0126420.

[29] Yates, J.R., Ruse, C.I. and Nakorchevsky, A. (2009) Proteomics by Mass Spectrometry: Approaches, Advances, and Applications. Annual Review of Biomedical Engineering, 11, 49-79. https://doi.org/10.1146/annurev-bioeng-061008-124934

[30] Wisniewski, M., Garbett, N., Fish, D., Brewood, G., Miller, J., Chaires, J. and Benight, A. (2011) Differential Scanning Calorimetry in Molecular Diagnostics. Vitro Diagnostic Technology, 17, 29-34.

[31] Garbett, N.C., Miller, J.J., Jenson, A.B. and Chaires, J.B. (2008) Calorimetry Outside the Box: A New Window into the Plasma Proteome. Biophysical Journal, 94, 1377-1383. https://doi.org/10.1529/biophysj.107.119453

[32] Garbett, N.C., Miller, J.J., Jenson, A.B. and Chaires, J.B. (2007) Calorimetric Analysis of the Plasma Proteome. Seminars in Nephrology, 27, 621-626.

https://doi.org/10.1016/j.semnephrol.2007.09.004

[33] Garbett, N.C., Miller, J.J., Jenson, A.B., Miller, D.M. and Chaires, J.B. (2007) Interrogation of the Plasma Proteome with Differential Scanning Calorimetry. Clinical Chemistry, 53, 2012-2014. https://doi.org/10.1373/clinchem.2007.091165

[34] Crane-Robinson, C., Read, C.M., Cary, P.D., Driscoll, P.C., Dragan, A.I. and Privalov, P.L. (1998) The Energetics of HMG Box Interactions with DNA. Thermodynamic Description of the Box from Mouse Sox-51. Journal of Molecular Biology, 281, 705-717. https://doi.org/10.1006/jmbi.1998.1895

[35] Jelesarov, I., Crane-Robinson, C. and Privalov, P.L. (1999) The Energetics of HMG Box Interactions with DNA: Thermodynamic Description of the Target DNA Duplexes1. Journal of Molecular Biology, 294, 981-995. https://doi.org/10.1006/jmbi.1999.3284

[36] Calderon, R.O., Stolowich, N.J., Gerlt, J.A. and Sturtevant, J.M. (1985) Thermal Denaturation of Staphylococcal Nuclease. Biochemistry, 24, 6044-6049. https://doi.org/10.1021/bi00343a004

[37] Manly, S.P., Matthews, K.S. and Sturtevant, J.M. (1985) Thermal Denaturation of the Core Protein of Lac Repressor. Biochemistry, 24, 3842-3846.

https://doi.org/10.1021/bi00336a004

[38] Chaires, J.B. (2010) Human Telomeric G-Quadruplex: Thermodynamic and Kinetic Studies of Telomeric Quadruplex Stability. The FEBS Journal, 277, 1098-1106. https://doi.org/10.1111/j.1742-4658.2009.07462.x

[39] Vesnaver, G. and Breslauer, K.J. (1991) The Contribution of DNA Single-Stranded Order to the Thermodynamics of Duplex Formation. Proceedings of the National Academy of Sciences, 88, 3569-3573. https://doi.org/10.1073/pnas.88.9.3569

[40] Splinter, R., van Herwaarden, A.W., Iervolino, E., Poel, G.V., Istrate, D. and Sarro, P.M. (2012) Analyzing Protein Denaturation Using Fast Differential Scanning Calorimetry. Procedia Engineering, 47, 140-143.

https://doi.org/10.1016/j.proeng.2012.09.104

[41] Garbett, N.C., Mekmaysy, C.S., Helm, C.W., Jenson, A.B. and Chaires, J.B. (2009) Differential Scanning Calorimetry of Blood Plasma for Clinical Diagnosis and Monitoring. Experimental and Molecular Pathology, 86, 186-191. 
https://doi.org/10.1016/j.yexmp.2008.12.001

[42] Adkins, J.N., Varnum, S.M., Auberry, K.J., Moore, R.J., Angell, N.H., Smith, R.D., Springer, D.L. and Pounds, J.G. (2002) Toward a Human Blood Serum Proteome: Analysis by Multidimensional Separation Coupled with Mass Spectrometry. Molecular \& Cellular Proteomics, 1, 947-955. https://doi.org/10.1074/mcp.M200066-MCP200

[43] Anderson, N.L. and Anderson, N.G. (2002) The Human Plasma Proteome: History, Character, and Diagnostic Prospects. Molecular \& Cellular Proteomics, 1, 845-867. https://doi.org/10.1074/mcp.R200007-MCP200

[44] Anderson, N.L. (2005) The Roles of Multiple Proteomic Platforms in a Pipeline for New Diagnostics. Molecular \& Cellular Proteomics, 4, 1441-1444. https://doi.org/10.1074/mcp.I500001-MCP200

[45] Garbett, N.C., Brock, G.N., Chaires, J.B., Mekmaysy, C.S., DeLeeuw, L., Sivils, K.L., Harley, J.B., Rovin, B.H., Kulasekera, K.B. and Jarjour, W.N. (2017) Characterization and Classification of Lupus Patients Based on Plasma Thermograms. PLoS ONE, 12, e0186398. https://doi.org/10.1371/journal.pone.0186398

[46] Fish, D.J., Brewood, G.P., Kim, J.S., Garbett, N.C., Chaires, J.B. and Benight, A.S. (2010) Statistical Analysis of Plasma Thermograms Measured by Differential Scanning Calorimetry. Biophysical Chemistry, 152, 184-190.

https://doi.org/10.1016/j.bpc.2010.09.007

[47] Merrell, K., Southwick, K., Graves, S.W., Esplin, M.S., Lewis, N.E. and Thulin, C.D. (2004) Analysis of Low-Abundance, Low-Molecular-Weight Serum Proteins Using Mass Spectrometry. Journal of Biomolecular Techniques, 15, 238-248.

[48] Garbett, N.C. and Brock, G.N. (2016) Differential Scanning Calorimetry as a Complementary Diagnostic Tool for the Evaluation of Biological Samples. Biochimica et Biophysica Acta, 1860, 981-989. https://doi.org/10.1016/j.bbagen.2015.10.004

[49] Mehdi, M., Fekecs, T., Zapf, I., Ferencz, A. and Lőrinczy, D. (2013) Differential Scanning Calorimetry (DSC) Analysis of Human Plasma in Different Psoriasis Stages. Journal of Thermal Analysis and Calorimetry, 111, 1801-1804. https://doi.org/10.1007/s10973-012-2468-2

[50] Michnik, A., Drzazga, Z., Michalik, K., Barczyk, A., Santura, I., Sozańska, E. and Pierzchała, W. (2010) Differential Scanning Calorimetry Study of Blood Serum in Chronic Obstructive Pulmonary Disease. Journal of Thermal Analysis and Calorimetry, 102, 57-60. https://doi.org/10.1007/s10973-009-0602-6

[51] Michnik, A., Drzazga, Z., Sadowska-Krępa, E. and Kłapcińska, B. (2014) Calorimetric Monitoring of the Effect of Endurance Training and Testosterone Treatment on Rat Serum Denaturation Transition. Journal of Thermal Analysis and Calorimetry, 115, 2231-2237. https://doi.org/10.1007/s10973-013-3611-4

[52] Szalai, Z., Molnár, T.F. and Lőrinczy, D. (2013) Differential Scanning Calorimetry (DSC) of Blood Serum in Chronic Obstructive Pulmonary Disease (COPD). Journal of Thermal Analysis and Calorimetry, 113, 259-264.

https://doi.org/10.1007/s10973-013-2999-1

[53] Garbett, N.C., Merchant, M.L., Chaires, J.B. and Klein, J.B. (2013) Calorimetric Analysis of the Plasma Proteome: Identification of Type 1 Diabetes Patients with Early Renal Function Decline. Biochimica et Biophysica Acta, 1830, 4675-4680. https://doi.org/10.1016/j.bbagen.2013.05.007

[54] Garbett, N.C., Merchant, M.L., Helm, C.W., Jenson, A.B., Klein, J.B. and Chaires, J.B. (2014) Detection of Cervical Cancer Biomarker Patterns in Blood Plasma and Urine by Differential Scanning Calorimetry and Mass Spectrometry. PLoS ONE, 9, 
e84710. https://doi.org/10.1371/journal.pone.0084710

[55] Joos, N., Garbett, N., Chaires, B., Bumpous, J., Zacharias, W. and Shumway, B. (2011) Serum and Saliva Analysis by Differential Scanning Calorimetry as a Novel Diagnostic Modality in Head and Neck Cancer: A Pilot Study. The Laryngoscope, 121. https://doi.org/10.1002/lary.22003

[56] Rai, S.N., Pan, J., Cambon, A., Chaires, J. and Garbett, N. (2013) Group Classification Based on High-Dimensional Data: Application to Differential Scanning Calorimetry Plasma Thermogram Analysis of Cervical Cancer and Control Samples. Open Access Medical Statistics, 3, 1-9. https://doi.org/10.2147/OAMS.S40069

[57] Krumova, S., Todinova, S., Danailova, A., Petkova, V., Dimitrova, K., Gartcheva, L. and Taneva, S.G. (2015) Calorimetric Features of IgM Gammopathies. Implication for Patient's Diagnosis and Monitoring. Thermochimica Acta, 615, 23-29.

https://doi.org/10.1016/j.tca.2015.07.002

[58] Todinova, S., Krumova, S., Gartcheva, L., Robeerst, C. and Taneva, S.G. (2011) Microcalorimetry of Blood Serum Proteome: A Modified Interaction Network in the Multiple Myeloma Case. Analytical Chemistry, 83, 7992-7998. https://doi.org/10.1021/ac202055m

[59] Todinova, S., Krumova, S., Radoeva, R., Gartcheva, L. and Taneva, S.G. (2014) Calorimetric Markers of Bence Jones and Nonsecretory Multiple Myeloma Serum Proteome. Analytical Chemistry, 86, 12355-12361. https://doi.org/10.1021/ac503677d

[60] Góralski, P., Rogalińska, M., Błoński, J.Z., Pytel, E., Robak, T., Kiliańska, Z.M. and Piekarski, H. (2014) The Differences in Thermal Profiles between Normal and Leukemic Cells Exposed to Anticancer Drug Evaluated by Differential Scanning Calorimetry. Journal of Thermal Analysis and Calorimetry, 118, 1339-1344. https://doi.org/10.1007/s10973-014-3957-2

[61] Chagovetz, A.A., Jensen, R.L., Recht, L., Glantz, M. and Chagovetz, A.M. (2011) Preliminary Use of Differential Scanning Calorimetry of Cerebrospinal Fluid for the Diagnosis of Glioblastoma Multiforme. Journal of Neuro-Oncology, 105, 499-506. https://doi.org/10.1007/s11060-011-0630-5

[62] Chagovetz, A.A., Quinn, C., Damarse, N., Hansen, L.D., Chagovetz, A.M. and Jensen, R.L. (2013) Differential Scanning Calorimetry of Gliomas: A New Tool in Brain Cancer Diagnostics? Neurosurgery, 73, 289-295. https://doi.org/10.1227/01.neu.0000430296.23799.cd

[63] Johnson, C.M. (2013) Differential Scanning Calorimetry as a Tool for Protein Folding and Stability. Archives of Biochemistry and Biophysics, 531, 100-109. https://doi.org/10.1016/j.abb.2012.09.008

[64] Zapf, I., Fekecs, T., Moezzi, M., Tizedes, G., Pavlovics, G., Kálmán, E., Horváth, P.O. and Ferencz, A. (2012) Differential Scanning Calorimetry of Blood Plasma in Breast Cancer Patients. Magyar Onkologia, 56, 274-279.

[65] Briere, L.-A.K., Brandt, J.-M. and Medley, J.B. (2010) Measurement of Protein Denaturation in Human Synovial Fluid and Its Analogs Using Differential Scanning Calorimetry. Journal of Thermal Analysis and Calorimetry, 102, 99-106. https://doi.org/10.1007/s10973-010-0794-9

[66] Than, P., Domán, I. and Lörinczy, D. (2004) Differential Scanning Calorimetry in the Research of Degenerative Musculoskeletal Disorders. Thermochimica Acta, 415, 83-87. https://doi.org/10.1016/j.tca.2003.09.015 